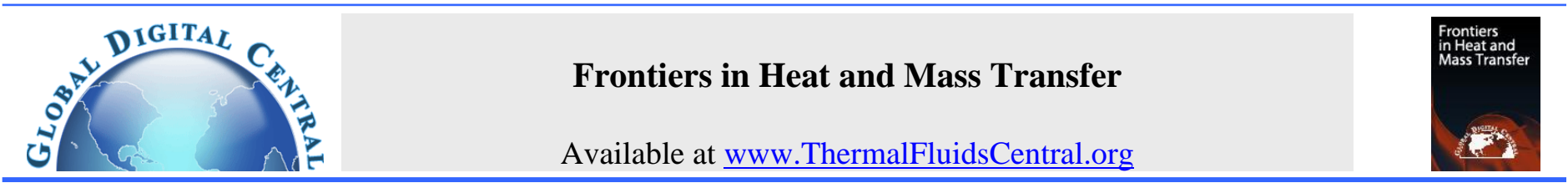

\title{
CFD ANALYSIS OF FREE CONVECTION IN NON-DARCIAN POROUS MEDIUM AND COMPARISON WITH SIMILARITY APPROACH
}

\author{
Elyazid Flilihi $^{\mathrm{a}, \dagger}$, Mohammed Sriti $^{\mathrm{b}}$, Driss Achemlal $^{\mathrm{a}}$, Mohamed El haroui $^{\mathrm{c}}$ \\ ${ }^{a}$ Sidi Mohamed Ben Abdellah University, Polydisciplinary Faculty of Taza, Engineering Sciences Laboratory, BP.1223, Taza, Morocco \\ ${ }^{\mathrm{b}}$ Moulay Ismail University, ENSAM Engineering School, Energy Department, Marjane 2, BP 15290, Al Mansour Meknes, Morocco \\ ${ }^{\mathrm{c}}$ Moulay Ismail University, Faculty of Sciences and Techniques, FST, Fluid Mechanic and Heat Transfer Laboratory, BP.509, Boutalamine,
}

Errachidia, Morocco

\begin{abstract}
In this work, a numerical simulation of steady and laminar free convection flow over a heated vertical flat plate embedded in a saturated porous medium by a Newtonian fluid is presented and analyzed. The Brinkman-Forchheimer extension of Darcy's law has been adopted to describe the movement of fluid within the porous matrix. A numerical solution of the governing continuity, momentum and energy equations was made with the appropriate boundary conditions using ANSYS/FLUENT software based on finite volume method. The found results are graphically presented and physically discussed for main controling parameters. Subsequently, we compared our CFD calculation by the results obtained with the similarity method in terms of temperature profiles for selected values of the Rayleigh number. It is essentially found that the increase in the Rayleigh number promotes the flow and the transfer of heat by convection in the porous medium.
\end{abstract}

Keywords: CFD calculation, boundary layer, free convection, non-Darcian Porous Medium, similarity Method.

\section{INTRODUCTION}

In recent years, considerable research efforts have been devoted to the study of heat transfer induced by buoyancy forces in a saturated porous medium by a Newtonian fluid. The interest for these natural convection phenomena has been motivated by such diverse engineering problem as of geothermal energy extraction, oil and gas extraction through the ground, cooling in nuclear reactors, buildings thermal insulation, the problem of drying agro-food products, etc,... Many principal past studies concerning these processes can be found in the books: (Nield and Bejan, 2017) and (Nield and Simmons, 2018).

Numerous studies have been reported in the past several decades using both Darcian and non-Darcian models for the porous medium. The Darcy model is applicable for slow flows but when the Reynolds number is greater than unity or in the case of high-speed flows, the Darcy model becomes inapplicable because it does not take account the inertial and viscous effects. These missing effects are very significant in most practical situations such as fluid flow in geothermal reservoirs, separation processes in chemical industries, thermal insulation, petroleum reservoir, and so on. These effects are incorporated by using the general flow known as Brinkman-Forchheimer extended Darcy model. The Brinkman's extension, which includes a viscous shear stress term in the momentum equation, has been used to account for the boundary effects. The inertial effects can be modelled through the addition of a quadratic term in veloc- ity, which is known as Forchheimer's extension. Therefore, the research interest in recent studies has been focused on the important non-Darcian phenomenon of convective heat transfer in porous media.

The computational Fluid Dynamics (CFD) provides an ability to simulate the complete heat transfer process, in different situations and for various geometric configurations with good accuracy. Recently, (Norris, 2009) has studied the numerical analysis of natural convection heat transfer for windows with porous screening material. After, (Rajesh et al., 2012) have been analyzed the laminar forced convection flow over a flat plate. In this study, the theoretical estimations of boundary layer thickness and heat transfer coefficient is examined using Computational Fluid Dynamics (CFD). These authors show that the boundary-layer thickness decreases with distance from the leading edge of the flat plate and increases with Reynolds number, also, the increasing in values of Reynolds number and Prandtl number tends to increase average and local Nusselt number. A few years later, (Shankar et al., 2017) have analyzed the influence of heat transfer process in porous media with air cavity, using the CFD approach. The numerical results obtained by these authors are validated with experimental results. Afterward, Flilihi et al. (2017) investigated the variable heat source and wall radiation effects on boundary layer convection from an inclined plate in non-Darcian porous medium. In this

${ }^{\dagger}$ Corresponding author. Email: elyazid_flilihi@yahoo.fr 
research, the problem is resolved numerically by a computational program based on the fifth order Runge-Kutta scheme coupled with shooting iteration technique. From the results, it can be concluded that, the thermal radiation promotes more the heat transfer to the porous medium, and leads to the expansion of the thermal boundary layer, and also, the importance of the buoyancy forces leads to a rapid cooling around the plate, and reduces the thermal boundary layer thickness. Furthermore, (Flilihi et al., 2019b) studied the semi-analytical prediction of mixed convection in porous medium using Darcy-Brinkman Model. Here, the obtained results indicate that the fluid suction along the plate stabilizes the velocity and the thermal boundary layer growth, on the other hand, the forced convection promotes the heat transfer in the boundary layer area. Recently, (Flilihi et al., 2019a) used the finite difference method for solving unsteady convective boundary layer flow past an inclined plate in a non-Darcian porous medium in the presence of the viscous dissipation effects using the Darcy-Brinkman-Forchheimer model. In this work, the obtained results show that the viscous dissipation and the inertial forces have a significant effect on the temperature field whereas the wall heat transfer rate is optimal for the vertical position of the plate. Also, Dharmaiah et al. (2019) have examined the unsteady MHD convective heat and mass transfer past a semi infinite inclined permeable moving plate embedded in a porous medium with thermal radiation and viscous dissipation. These authors found that, the effect of increasing values of the viscous dissipation parameter or the Eckert number is to enhance the velocity and temperature fields. In addition, it was found that the the Nusselt number decreased as the heat radiation coefficient was increased. Huang et al. (2019) have analysed numerically the heat and mass transfer characteristics of the influence of uniform blowing/suction and MHD (magnetohydrodynamic) on the free convection of non-newtonian fluids over a vertical plate in porous media with internal heat generation and soret/dufour effects. The results indicate that when the magnetic field parameter $\mathrm{M}$ and the non-Newtonian fluid $\mathrm{n}$ increase, the local Nusselt number decrease. Otherwise, increasing the internal heat generation coefficient $A^{*}$ reduces the local Nusselt number. In the case of suction, the local Nusselt number increase.

Very recently, The effects of variable viscosity on steady, laminar heat and mass transfer by hydromagnetic mixed convection flow along a vertical cylinder embedded in a non-darcy porous medium are numerically analyzed by Mohammad (2020). It found that increasing the values of power law index, curvature parameter and buoyancy ratio leads to enhance the local Nusselt and Sherwood numbers. The local Nusselt and Sherwood numbers weaken as the inertia effect parameter and the square of the Hartmann number increases. The raise in the value of the Lewis number decreases the rate of heat transfer while increases the rate of mass transfer. For lower values of viscosity, the heat transfer increased for both gases and liquids, while the mass transfer decreased for gases and increased for liquids. Also, (Rani et al., 2020) theoretically studied the effects of diffusion-thermo, radiation-absorption and Hall and ion slip effects on MHD free convective rotating flow of the metallic nanoparticles past a moving semi-infinite vertical porous plate with constant heat source. Here, the authors found that The skin friction coefficient decreases with the increasing Hall and ion slip parameter, permeability parameter and Radiation absorption parameter, also, the Nusselt number decreases with radiation absorption parameter and Dufour parameter.

The aim of the current study will focus on the study of free convection heat transfer along an isothermal vertical plate embedded in a non-Darcian porous medium. The simulations is made using ANSYS FLUENT code to analyze the effect of Rayleigh number on the thermal field in the boundary layer area, and to predict the the heat transfer rate profile at the surface of the plate. This study finds applications in the fields of petroleum engineering, geothermal energy, etc...

\section{NUMERICAL MODELING AND ASSUMPTIONS}

The problem is to study the free convection flow around a heated vertical plate embedded in a non-Darcian saturated porous medium by a Newtonian fluid as shown in figure 1 . The temperature of the plate is raised to $T_{w}$, which is then maintained constant. $T_{\infty}$ is the temperature away from the plate assumed constant. The flow is assumed two dimensional, stationary, and laminar for an incompressible fluid, and the Cartesian coordinates $x$ and $y$ are measured, respectively, perpendicular and along to the plate. The convective fluid and the porous medium are supposed in local thermodynamic equilibrium. The boundary effects and convective term are all considered in the momentum equation.

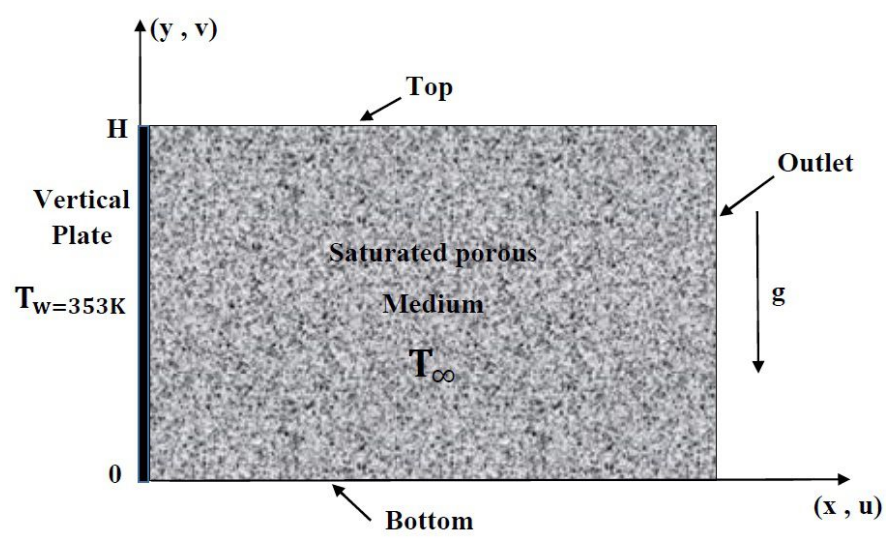

Fig. 1 Physical model and coordinate system.

The porous zone is treated as a fluid zone where the pressure drop is simulated by adding a source term $S_{i}(1)$ in the momentum equation (3). $S_{i}$ is defined as the sum of viscous loss term (the Darcy's term, the first one on the right hand side of (1)) and of the inertial loss term (the second one on the right-hand side of (1)). The permeability and the inertial resistance values of a porous aluminum layer are taken from the experimental results $\left(\alpha=1.136 .10-11 \mathrm{~m}^{2}\right.$ and $\left.C_{2}=0,468 \mathrm{~m}^{-1}\right)$ (obtained by Lage et al. (1997)). In general, the governing equations used by ANSYS/FLUENT software. for the case of an isotropic porous medium and for a single-phase flow are given by (2), (3) and (4): see Refs, ANSYS Fluent User's Guide, (ANSYS Inc, 2011) and Gascoin et al. (2013)).

$$
\begin{gathered}
S_{i}=-\frac{\mu}{\alpha} v_{i}+\frac{1}{2} C_{2}|v| v_{i} \\
\frac{\partial \gamma \rho}{\partial t}+\nabla \cdot(\gamma \rho \vec{v})=0 \\
\frac{\partial \gamma \rho \vec{v}}{\partial t}+\nabla \cdot(\gamma \rho \vec{v} \cdot \vec{v})=-\gamma \nabla p+\nabla(\gamma \vec{\tau})+\gamma \rho \vec{g}-S_{i} \\
\frac{\partial}{\partial t}\left(\gamma \rho_{f} E_{f}+(1-\gamma) \rho_{s} E_{s}\right)+\nabla \cdot\left(\vec{v}\left(\rho_{f} E_{f}+P\right)\right) \\
=\nabla \cdot\left[k_{e f f} \nabla T-\left(\Sigma_{i} h_{i} \vec{J}_{i}\right)+(\vec{\tau} \cdot \vec{v})\right]+S_{f}^{h}
\end{gathered}
$$

where, $S_{i}$ is the source term for the $i^{\text {th }}(x$ or $y$ ) momentum equation, $|v|$ is the magnitude of the velocity. $\mu, \alpha, C_{2}, g E_{f}, E_{s}, \rho_{f}, \rho_{f}, \gamma, k_{e f f}$ and $S_{f}^{h}$, are respectively, fluid viscosity, permeability of porous medium, the inertial loss coefficient, the gravitational acceleration, the total fluid energy, the total solid medium energy, the fluid density, the solid medium density, the porosity of the medium, the effective thermal conductivity of the medium and the fluid enthalpy source term.

The effective thermal conductivity in the porous medium is computed as the volume average of the fluid conductivity and the solid conductivity:

$$
k_{e f f}=\gamma k_{f}+(1-\gamma) k_{s}
$$

where, $k_{f}$ and $k_{f}$ are respectively, the fluid phase thermal conductivity and the solid medium thermal conductivity. 


\subsection{Prandtl number}

The Prandtl number defined as the ratio of momentum diffusivity to thermal diffusivity, is given as:

$$
\operatorname{Pr}=\frac{\nu}{a}
$$

\subsection{Grashof number}

The Grashof number is the ratio of the buoyancy forces to viscous forces acting on a fluid.

$$
G r=\frac{g \beta\left(T_{w}-T_{\infty}\right) H^{3}}{\nu^{2}}
$$

Where $\mathrm{H}$ is the length of plate.

\subsection{Rayleigh number}

The Rayleigh number is a product of the Grashof and Prandtl numbers and compares the buoyancy and momentum forces to the viscous forces and thermal diffusivity of the fluid. The Rayleigh Number is used to define the transition of natural convection flow from laminar to turbulent. The Rayleigh number is given as:

$$
R a=G r \cdot \operatorname{Pr}=\frac{g \beta\left(T_{w}-T_{\infty}\right) H^{3}}{\nu a}
$$

\subsection{Nusselt number}

The Nusselt number is defined as the ratio between heat flux with and without convection:

$$
N u=\frac{Q \cdot H}{k\left(T_{w}-T_{\infty}\right)}
$$

Where $\mathrm{k}$ is the thermal conductivity of air, $\mathrm{Q}$ is the heat flux, $T_{w}$ and $T_{\infty}$ are respectively, the temperature of the plate, and the fluid reference temperature. the heat flux $\mathrm{Q}$ is given by:

$$
Q=h \cdot\left(T_{w}-T_{\infty}\right)
$$

Where $\mathrm{h}$ is the convective heat transfer coefficient.

\section{NUMERICAL SETUP}

The typical mesh adopted in this study, illustrated in figure 2.

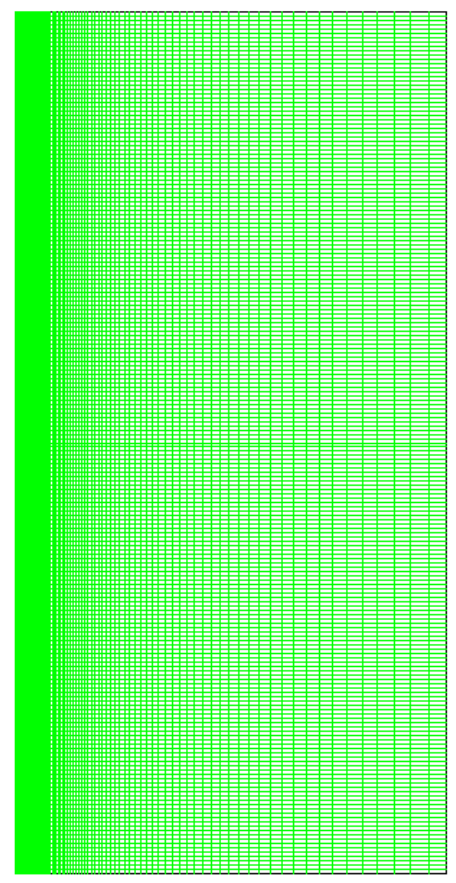

Fig. 2 Mesh used for our simulations.
Physically, the thickness of the boundary layer is much smaller than any characteristic length defined in the streamwise direction. Therefore, the changes in physical properties in the direction parallel to the plate are small compared to the corresponding changes in perpendicular to the plate. Thus, grids in the $\mathrm{x}$ direction should be much finer close to the plate and spaced elsewhere.

The simulations presented in this study, as the simulations in steady state using the pressure-based solver. The laminar model is adopted. The pressure-velocity scheme used was SIMPLE "Semi-Implicit Method for Pressure Linked-Equations", and the buoyancy was modeled using the Boussinesq approximation.

The standard method was used for pressure and second order upwind schemes were used for calculating momentum and energy. These are all commonly used in solving natural convection simulations.

\subsection{Boundary conditions}

The temperature of the bottom, of the top and of the outlet respectively, was set to $300 \mathrm{~K}$. The boundary conditions adopted in this study for all simulations using Ansys Fluent solver are presented below in table 1.

Table 1 Boundary conditions used in Ansys Fluent simulations.

\begin{tabular}{|c|c|}
\hline Zone & Type of the Boundary condition \\
\hline Plate & Wall \\
\hline Top & Pressure-outlet \\
\hline bottom & Pressure-inlet \\
\hline Outlet & Symmetry \\
\hline
\end{tabular}

\subsection{Convergence criteria}

In this model, the minimum value the residuals reach convergence were set according to the values shown in table 2 . If the model converged to this minimum, the residuals levelled off and no longer decreased. and therefore the calculations are allowed.

Table 2 Residual limits.

\begin{tabular}{|c|c|c|c|}
\hline Continuity & $X$-Velocity & $Y$-Velocity & Energy \\
\hline $1 e^{-06}$ & $1 e^{-06}$ & $1 e^{-06}$ & $1 e^{-06}$ \\
\hline
\end{tabular}

\section{NUMERICAL RESULTS AND DISCUSSION}

A numerical investigation has been made for steady laminar and two dimensional thermal convective flow along heated a vertical plate embedded in non-Darcian porous medium. The CFD Ansys Fluent solver was used to analyze the effect of the Rayleigh number on the thermal field, and to predict the heat transfer rate profile at the surface of the plate. The Rayleigh number has been varied as function of length of the plate $H$ from $10^{2}$ to $10^{6}$. The principale results are presented and discussed below.

In figure 3 the steady state temperature profiles as a function of $x$ for different positions $y$ along of the plate are plotted. This figure shows that the cooling of the medium is all the slower when passing from the leading edge to the upper part of the plate. This can be explained physically by the existence of a large amount of energy in this part of the plate.

Figure 4 displays the thermal field for the Rayleigh number $R a=$ $5,58.10^{2}$. Here, the isothermal lines distribution in the boundary layer 


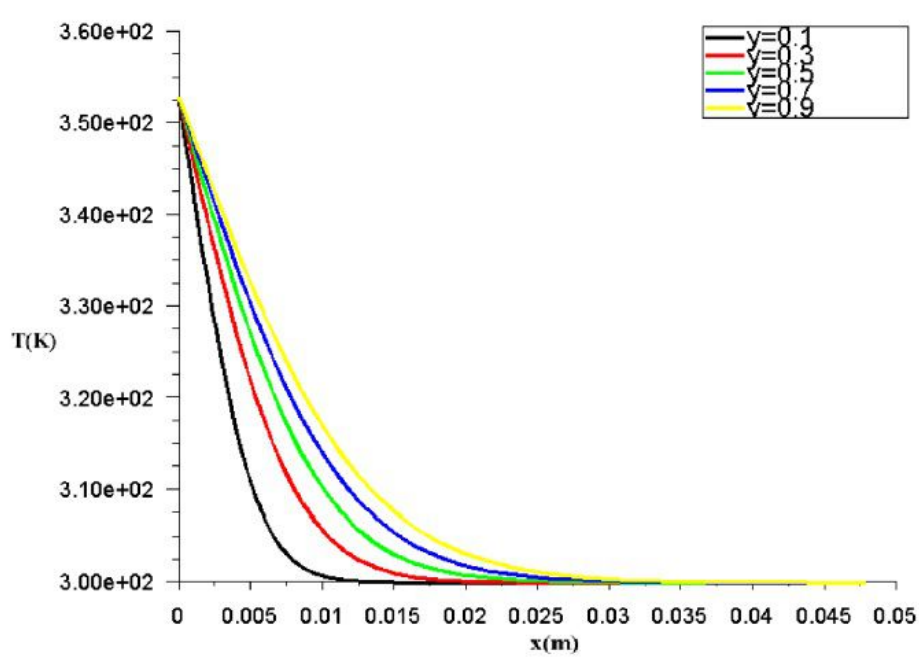

Fig. 3 Temperature profiles at selected position along the plate.

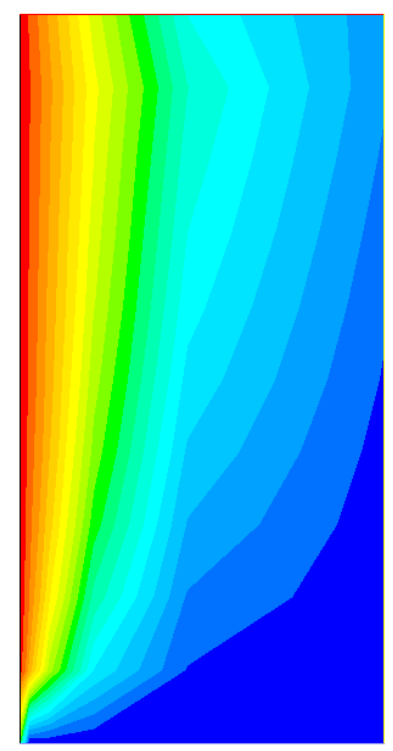

Fig. 4 Temperature Contours for Rayleigh number: $R a=5,58 \cdot 10^{2}$.

area can be explained by the existence of the effect of heat transfer by conduction and convection in combined mode, from the heated plate to the medium.

Figures from 5 to 7 show the effect of Rayleigh number on the thermal field distribution in the boundary layer area of an isothermal plate $\left(T_{w}=353 \mathrm{~K}\right)$, placed in a saturated non-Darcian porous medium. From these figures, we notice that the isothermal lines are confined near the hot vertical wall. This shows that for the values of the Rayleigh number $R a$ greater than the critical value $R a=10^{3}$, the heat transfer in the medium occurs by convection. On the other hand, we have also noticed that the large values of $R a$ leads to the intensification of natural convection.

The local Nusselt number profile is showns in figure 8 . The results indicate that the heat transfer rate is important at the leading edge of the plate, and we notice that it decreases rapidly passing from the leading edge to the other end of the plate.
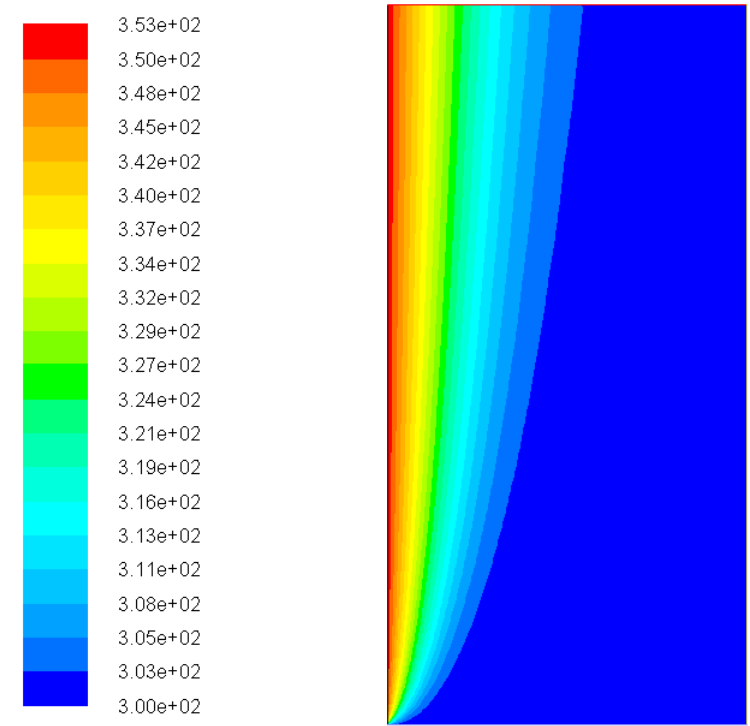

Fig. 5 Temperature contours for Rayleigh number: $R a=4,46.10^{3}$.
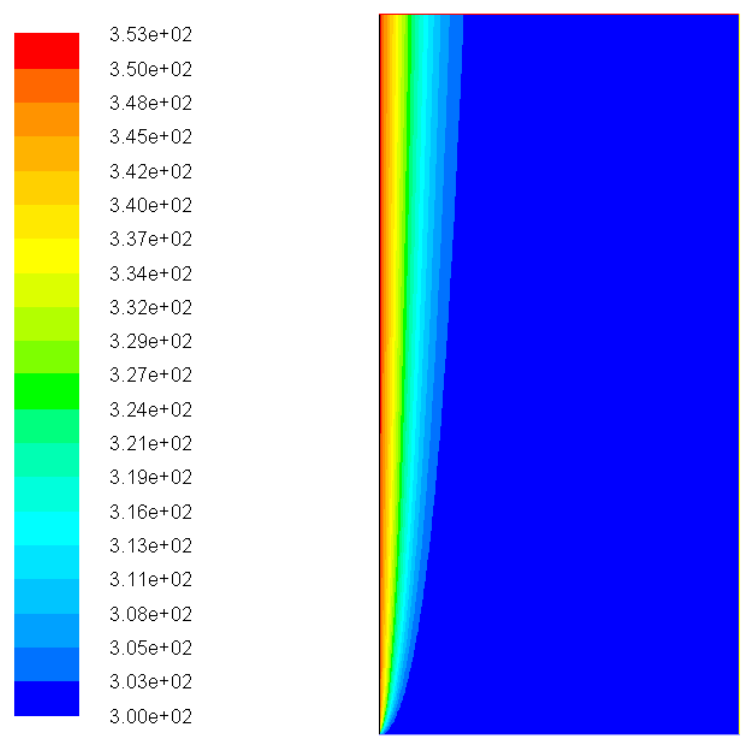

Fig. 6 Temperature contours for Rayleigh number: $R a=1,2.10^{5}$.

\section{COMPARISON OF CFD CALCULATION WITH SIMILARITY METHOD}

The similarity method results found by Flilihi et al. $(2017,2019 b)$ are validated with those published in the literature and they showed a very good agreement.

In this section, we compared the results obtained by ANSYS FLUENT simulations with those the similarity approach, for the case of a laminar, two-dimensional and stationary thermal convection flow along a heated vertical plate embedded in a non-Darcian porous medium, based on the Darcy-Brinkman-Forchheimer model, in the absence of internal heat source, the thermal radiation and the viscous dissipation effects.

Figures 9, 10, 11 and 12 show, at $\operatorname{Pr}=0.71$, the temperature profiles as a function of $x$ at selected position along of the plate, for $R a=1.5310^{3}$ and $R a=1.2210^{4}$ respectively. From these figures, we note that the CFD approach gives good results and the less computation time is required. Also, the CFD results showed an error of $5 \%$ compared to the solutions obtained by the similarity method, indicating a performance of the CFD approach for the case studied. 

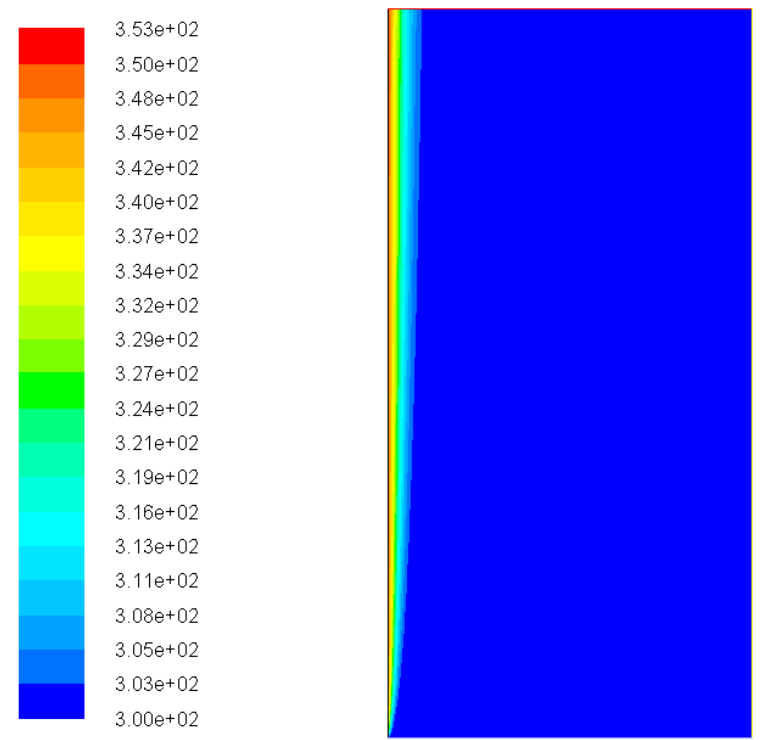

Fig. 7 Temperature contours for Rayleigh number: $R a=4,46 \cdot 10^{6}$.

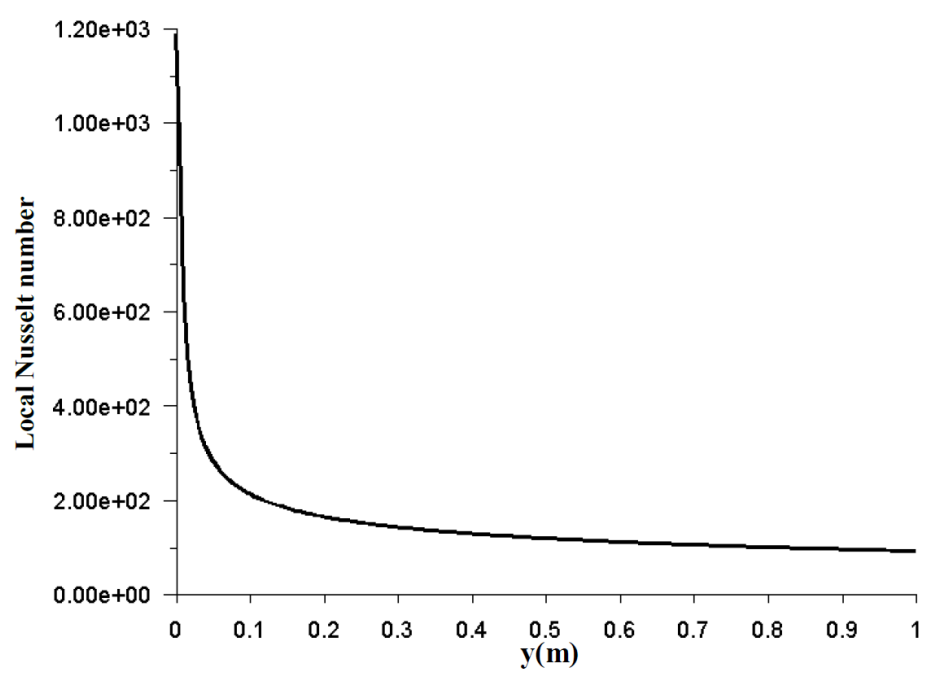

Fig. 8 Local Nusselt number profile as a function of y position along of the plate.

\section{CONCLUSION}

A two-dimensional numerical study of stationary laminar flow and free convection in the boundary layer area of a heated vertical plate embedded in a saturated non-Darcian porous medium was carried out. To simulate the flow and the heat transfer in porous medium, the Darcy-BrinkmanForchheimer model was used. The governing boundary layer equations are numerically solved using the ANSYS FLUENT software. Then, the found thermal profiles by the CFD approach, for selected values of Rayleigh number Ra was compared with those deduced by using the similarity method. From the present study we have found that:

1. The results of this study were in good agreement with those of the similarity method.

2. This investigation shows that the CFD approach is able to evaluate the convective transfer coefficient between the surface and the porous medium.

3. The buoyancy forces accelerate the cooling in the boundary layer area and consequently reduce the thermal boundary layer thickness.

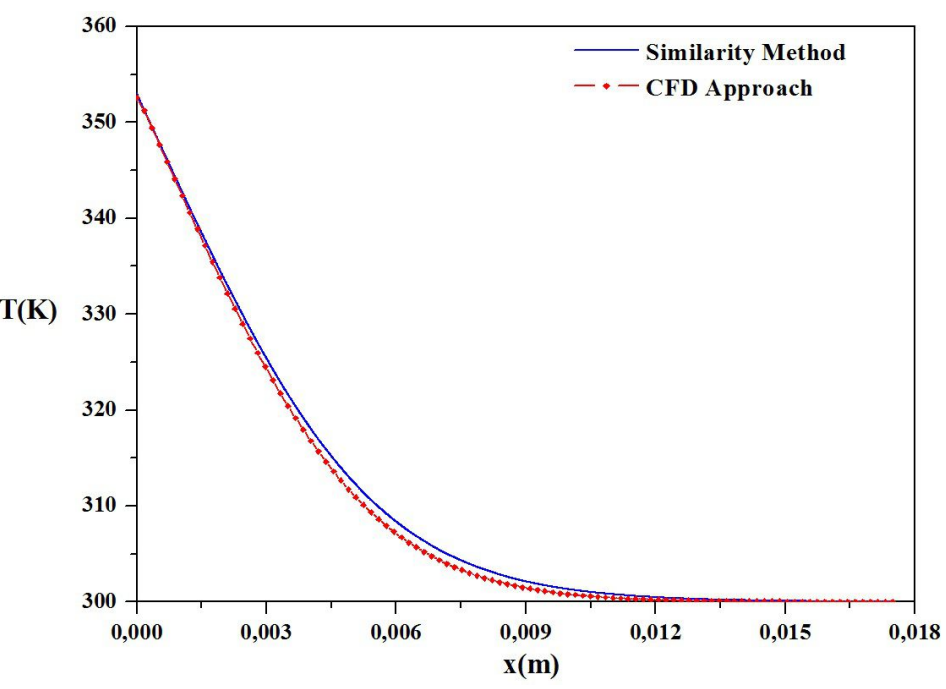

Fig. 9 Temperature profiles as a function of $\mathrm{x}$ for $R a=1.5310^{3}$ at $y=H / 2$.

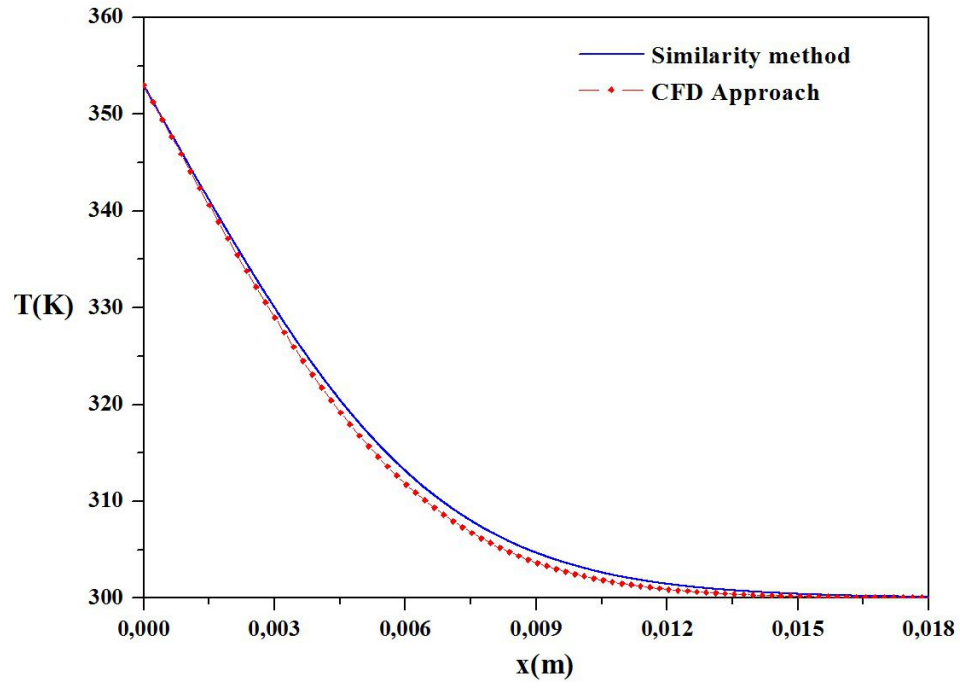

Fig. 10 Temperature profiles as a function of $\mathrm{x}$ for $R a=1.5310^{3}$ at $y=3 H / 4$.

4. Increasing the Rayleigh number promotes the flow and convective heat transfer in the porous medium.

5. The heat transfer by convection becomes predominant in the medium, when the value of the Rayleigh number is greater than a critical value given approximately by $R a=10^{3}$.

6. The wall heat transfer rate is important at the leading edge of the plate.

7. The local Nusselt number along the plate surface decreases quickly with y coordinate.

\section{REFERENCES}

ANSYS Inc, 2011, ANSYS Fluent User's Guide, Version 14.0, Canonsburg, USA.

Dharmaiah, G., Chamkha, A.J., Vedavathi, N., and Balamurugan, K., 2019, "Viscous dissipation effect on transient aligned magnetic free convective flow past an inclined moving plate," Frontiers in Heat and Mass 


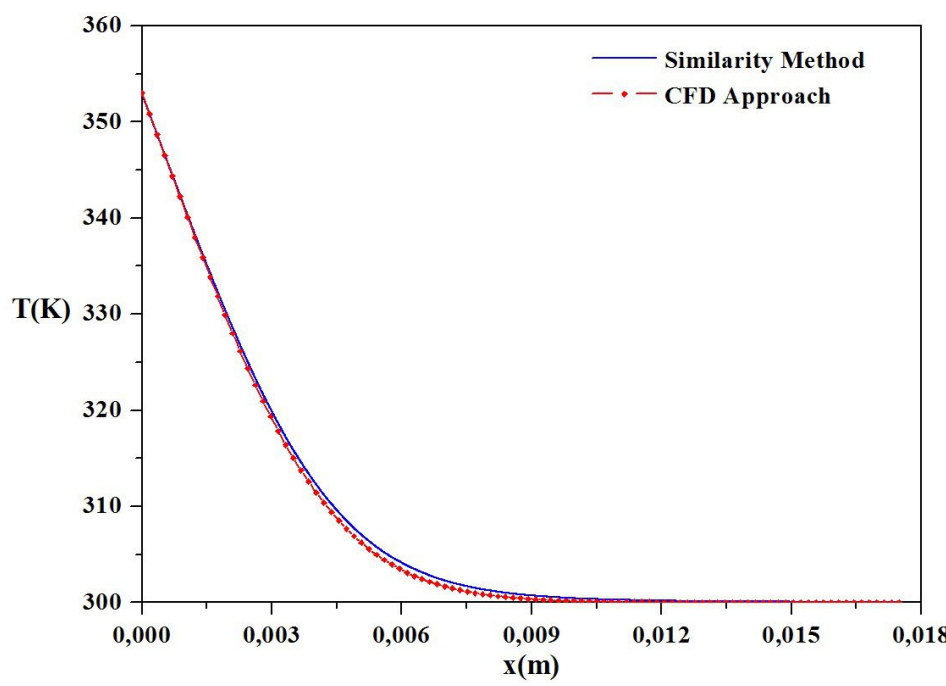

Fig. 11 Temperature profiles as a function of $\mathrm{x}$ for $R a=1.2210^{4}$ at $y=H / 2$.

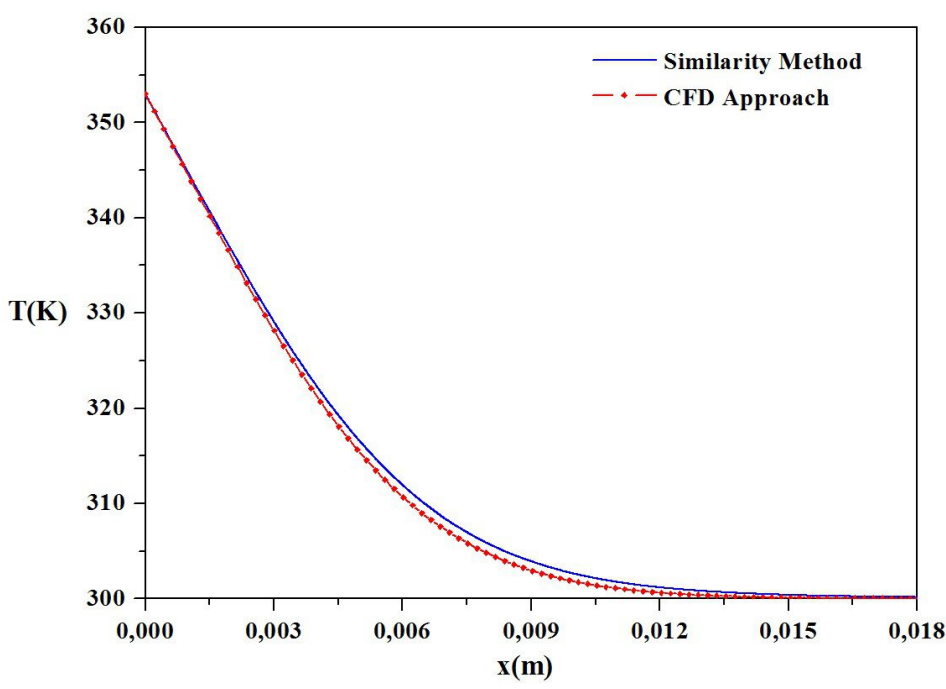

Fig. 12 Temperature profiles as a function of $\mathrm{x}$ for $R a=1.2210^{4}$ at $y=3 H / 4$.

\section{Transfer(FHMT), 12(17).}

http://dx.doi.org/10.5098/hmt.12.17.

Flilihi, E., Sriti, M., and Achemlal, D., 2019a, "Numerical solution on non-uniform mesh of Darcy-Brinkman-Forchheimer model for transient convective heat transfer over flat plate in saturated porous medium," Frontiers in Heat and Mass Transfer(FHMT), 12(12).

http://dx.doi.org/10.5098/hmt.12.12.

Flilihi, E., Sriti, M., Achemlal, D., and El Haroui, M., 2017, "Variable heat source and wall radiation effects on boundary layer convection from an inclined plate in non-darcian porous medium," Frontiers in Heat and
Mass Transfer(FHMT), 9(23).

http://dx.doi.org/10.5098/hmt.9.23.

Flilihi, E., Sriti, M., Achemlal, D., and El Haroui, M., 2019b, "Semianalytical prediction of mixed convection in porous medium using DarcyBrinkman model," Journal of Engineering and Applied Sciences, 14, 1122-1129. https://dx.doi.org/10.36478/jeasci.2019.1122.1129.

Gascoin, N., Romagnosi, L., and Fedioun, I., 2013, "Pyrolysis in porous media: part 2. numerical analysis and comparison to experiments," Journal of Porous Media, 16(9), 857-873.

https://dx.doi.org/10.1615/JPorMedia.v16.i9.60.

Huang, C.J., Hsu, H.P., and Ay, H.C., 2019, "Influence of mhd on free convection of non-newtonian fluids over a vertical permeable plate in porous media with internal heat generation," Frontiers in Heat and Mass Transfer(FHMT), 13(14).

http://dx.doi.org/doi:10.5098/hmt.13.14.

Lage, J., Antohe, B., and Nield, D., 1997, "Two types of nonlinear pressure-drop versus flow-rate relation observed for saturated porous media," Journal of Fluids Engineering, 119(3), 700-706.

https://dx.doi.org/10.1115/1.2819301.

Mohammad, S.A., 2020, "Effects of variable viscosity on heat and mass transfer by mhd mixed convection flow along a vertical cylinder embedded in a non-darcy porous medium," Frontiers in Heat and Mass Transfer (FHMT), 14(7).

https://dx.doi.org/10.5098/hmt.14.7.

Nield, D.A., and Bejan, A., 2017, Convection in porous media, 5th ed., Springer Science, New York - USA.

https://doi.org/10.1007/978-3-319-49562-0.

Nield, D.A., and Simmons, C., 2018, A Brief introduction to convection in porous media, Springer Nature.

https://doi.org/10.1007/s11242-018-1163-6.

Norris, N., 2009, Numerical Analysis of Natural Convection Heat Transfer for Windows with Porous Screening Material, M.A.Sc. Thesis, University of Waterloo.

Rajesh, K., Pankaj, A., Mohan, G., and Jitendra, A., 2012, "Laminar flow analysis over a flat plate by computational fluid dynamics," International Journal of Advances in Engineering \& Technology (IJAET), 3(2), 756764.

Rani, C.B., Vedavathi, N., Balamurugan, K., and Dharmaiah, G., 2020, "hall and ion slip effects on ag - water based mhd nanofluid flow over a semi-infinite vertical plate embedded in a porous medium," Frontiers in Heat and Mass Transfer (FHMT), 14(6).

http://dx.doi.org/10.5098/hmt.14.6.

Shankar, V., Bengtson, A., Fransson, V., and Hagentoft, C., 2017, "Influence of Heat Transfer Process in Porous Media with Air Cavity A CFD Analysis," Proceedings of the 4th International Conference of Fluid Flow Heat and Mass Transfer (FFHMT'17), 161, Toronto, Canada. https://dx.doi.org/10.11159/ffhmt17.161. 